\title{
The Effect of Convection on the Thermal Power Change of Loop Thermosyphon
}

\author{
Mária Polačiková ${ }^{1, *}$, Andrej Kapjor ${ }^{1}$, Milan Malcho ${ }^{1}$, and Patrik $\mathrm{Nemec}^{1}$ \\ ${ }^{1}$ University of Žilina, Department of Power Engineering, Univerzitná 8215/1, Slovakia
}

\begin{abstract}
Creating thermal well-being and comfort for humans is now very natural and necessary. From the point of view of ensuring optimal operating conditions for electronic and electrical equipment, it is very important to provide a cooling system. For this reason, the research work deals with the creation of optimal conditions for rising temperatures in rooms with electronics. A combination of cooling systems is proposed to reduce the heat load of electronic components. The first part of the work generally describes the requirements for the design of refrigeration equipment and methods of heat dissipation by natural or forced convection. Depending on the requirement for low-energy equipment, a cooling system with a gravitational heat pipe and fans was designed in the second part of the work. The cooling system was installed in a closed electrical cabinet. The resulting values of the measurements indicated the evaluation of the transferred heat output in free and forced convection. The research also points to a comparison of the individual flow directions created by the fans.
\end{abstract}

\section{Introduction}

Adjusting the temperature and properties of the air in a room is now a natural part of a person's comfort. Various devices that have been manufactured directly are used to increase, decrease the temperature or to adjust the humidity. Most of them depend on the source of electricity in their activities. Scientists are trying to replace this energy dependence in a more economical and independent way. Many research works therefore focus on the use of passive methods in ensuring the thermal comfort of a person or on the maintenance-free and safe operation of equipment. This scientific work, which focuses on cooling systems in electrical engineering, is also moving in the direction of passive operation of equipment.

Electrical equipment is operated in individual application areas, in different climatic conditions and the requirements for their operation are determined according to the purpose. The development of electrical components is focused on ever higher performance and functional usability of space, high efficiency, reliability and also to a higher technological level. With the improvement of the devices, there is a constant increase in the local heat load, which is caused by heat losses on the conductors. The increased amount of

\footnotetext{
*Corresponding author: maria.polacikova@,fstroj.uniza.sk
} 
heat produced, which is in homogeneously distributed over space causes deterioration of the parameters of electronic devices or their malfunction $[1,2]$. From this point of view, it is necessary to design a separate cooling system when designing electrical equipment. New cooling technologies must meet the requirements and limitations related to the design of high-performance electronic equipment, optimal production costs and other parameters [3]:

- Required temperature in the electrical equipment - depends on the specific electrical components that are inside the electrical cabinet. Neither high nor low temperatures are unsatisfactory. It is generally known that the surface temperature in an electrical device should not fall below the dew point temperature.

- Ambient air temperature - affects the choice of cooling method. In case of ambient air temperature lower than the required operating temperature in the cabinet, natural heat dissipation can be used. In case of insufficient heat dissipation without active elements, it is possible to support heat exchange by means of fans.

- Required cooling capacity - is the result of the sum of heat loss of individual components in the electrical cabinet and the heat that comes from the environment. The location of the electrical cabinet in the room has a significant effect on the cooling system. Design software is also used to calculate the required cooling capacity.

- Distribution of electrical components - ensures even airflow around all electrical components in the electrical cabinet. When designing a cooling system, it is important to properly direct the direction of cold air flow so that the heat loss is dissipated proportionally.

\section{Existing methods of heat dissipation}

The primary goal of any cooling system is to increase the performance and reliability of the cooled modules, which is closely related to temperature. In principle, temperature plays a major role in the long-term reliability of the device, as many electrical parameters depend on it. The choice of the cooling system therefore focuses primarily on the intensity of the accumulated thermal energy in the space, on the operating conditions of the equipment (dimensions, ambient temperature) and finally on the energy and economic efficiency of the system used [2].

The basic division of the method of heat dissipation in electrical engineering is according to the type of convection, which can be natural or forced. The individual types of convection in the electrical cabinet are shown in Figure 1. Natural convection is advantageous due to its simplicity and maintenance-free system. It belongs to the passive methods of heat dissipation together with immersion cooling and various types of heat pipes. The passive cooling method is independent of external energy sources. In practice, it occurs, for example, when cooling printed circuit boards up to $5 \mathrm{~W}$. Classic residential or administrative distribution cabinets are designed on the basis of natural cooling by heat transfer between the cabinet wall and the surrounding environment. This type of cooling is characterized by a higher temperature drop and larger dimensions of the heat exchange surface. A relatively stable ambient temperature with low relative humidity is assumed. If these conditions are not met, due to power losses of the electrical equipment of the switchboard, it becomes overheated and some possible devices fail. Failure also occurs due to low temperatures and humidity. It is for this reason that it is necessary to keep the internal temperature of the switch cabinets in a relatively narrow temperature range $[4,5]$.

Where natural convection is not an adequate cooling solution, usually due to size and volume limitations, external means for providing forced air convection, such as fans and pumps, are used. Their choice depends on the possibility of using outside air (e.g. fan or air/air heat exchanger) or on cooling to a lower temperature than the ambient air temperature (cooling units or water/air heat exchanger). These devices are active cooling 
methods because they use an external energy source to reach the required temperature. The forced flow of cold air in a room with electronic or electrical equipment achieves increased heat dissipation from individual parts of the device and achieves an even temperature distribution throughout the room. The point overheating of the individual components is also reduced. Forced convection cooling can increase the heat transfer coefficient by 5 to 12 times compared to natural convection. One of the disadvantages of forced cooling is the mixing of indoor and outdoor air. For this reason, it is necessary to secure the dust filters against the ingress of dirt. Other additional equipment of the cooling system affects costs, reliability, ease of operation and acoustic levels [2, 4, 5].
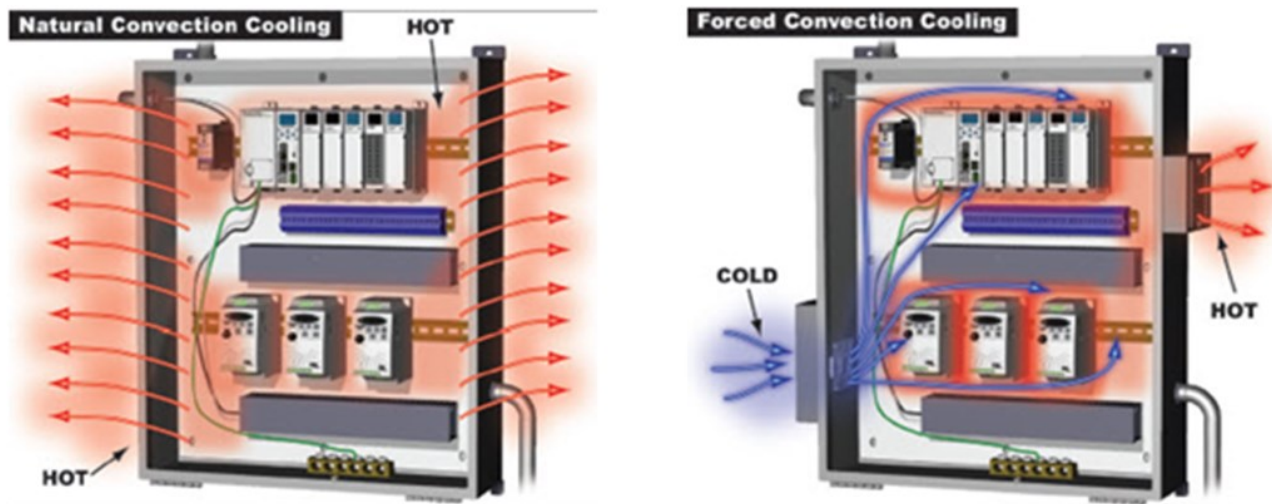

Fig. 1. The course of temperatures in the interior of the cabinet during the natural flow of air to the heat pipe [6].

With regard to the above-mentioned positive and negative aspects of individual cooling systems in electrical engineering, the scientific work focuses on their joint combination and creation of a low-energy, efficient and especially high-performance system. For this reason, the research focused on the method of passive heat dissipation in electrical engineering using a heat pipe. The issue of heat transfer between the evaporator and condenser in the heat pipes was also addressed in the Fluent modelling program [7]. Other scientific works on the subject describe the limitations associated with heat transfer in a heat pipe [8]. The research work of the scientific team in France offers a certain overview of the cooling systems in the data centres [9]. Scientific findings on forced cooling in telecommunications centres were presented by Delgado together with the scientific team in his work [10]. Research by Sun, Zhang and Liao has focused on the use of the gravitational heat pipe in electronics [11]. Thanks to this knowledge of the issue, a gravity loop heat pipe was also selected. This type of heat pipe ensures continuous heat transfer based on phase changes of the working substance with a minimum temperature difference and without any external energy sources. Each heat pipe needs to be filled with working fluid during its operation. Due to the effect of heat, the state of the work charge changes, and thus heat transfer takes place. From the results of the study on the influence of the amount of working substance on the heat output in the heat pipe, it was concluded that a suitable filling of the heat pipe with the working substance is around $50 \%$ [12].

\section{Experimental apparatus and procedure}

The research work is focused on the cooling of electronic elements that are stored in the interior of the electrical cabinet. The electrical cabinet is sealed and isolated from external environmental influences. A cooling system with a gravity loop heat tube is proposed, 
which is gradually loaded with different amounts of heat flow. Thanks to their design, these tubes are flexible and can transmit heat flux over a distance of $10 \mathrm{~m}$. The pipe diameter can be up to $30 \mathrm{~mm}$. With a slight increase in the diameter of the transport pipe, it is possible to achieve heat transfer over longer distances. The maximum operating temperature of the electronic components is around 70 to $80^{\circ} \mathrm{C}$. The working substance ensuring the heat transfer in the heat pipe itself is water [13].

In general, the design of gravity loop heat pipes consists of an evaporator, a condenser, a supply line (vapour phase stream of the working substance) and a return line (working phase liquid phase stream). The layout of the individual parts of the heat pipe must be arranged so that the condenser is located above the evaporator. This method of placing the individual parts ensures the flow of the working medium in the gravitational field. The schematic layout of the entire experimental cooling system in the electrical cabinet is shown in Figure 2, showing the longitudinal and perpendicular flow of air to the evaporator. The evaporating part of the heat pipe is located in the interior of the electrical cabinet with the dimensions of the inner space of the cabinet. The condensing section was dimensioned according to the evaporator section so as to remove the same amount of heat as was supplied to it from the evaporator. The capacitor housing is mounted outdoors on the electrical cabinet. The entire cooling system is complemented by an external fan, which ensures more intensive heat removal from the condenser.

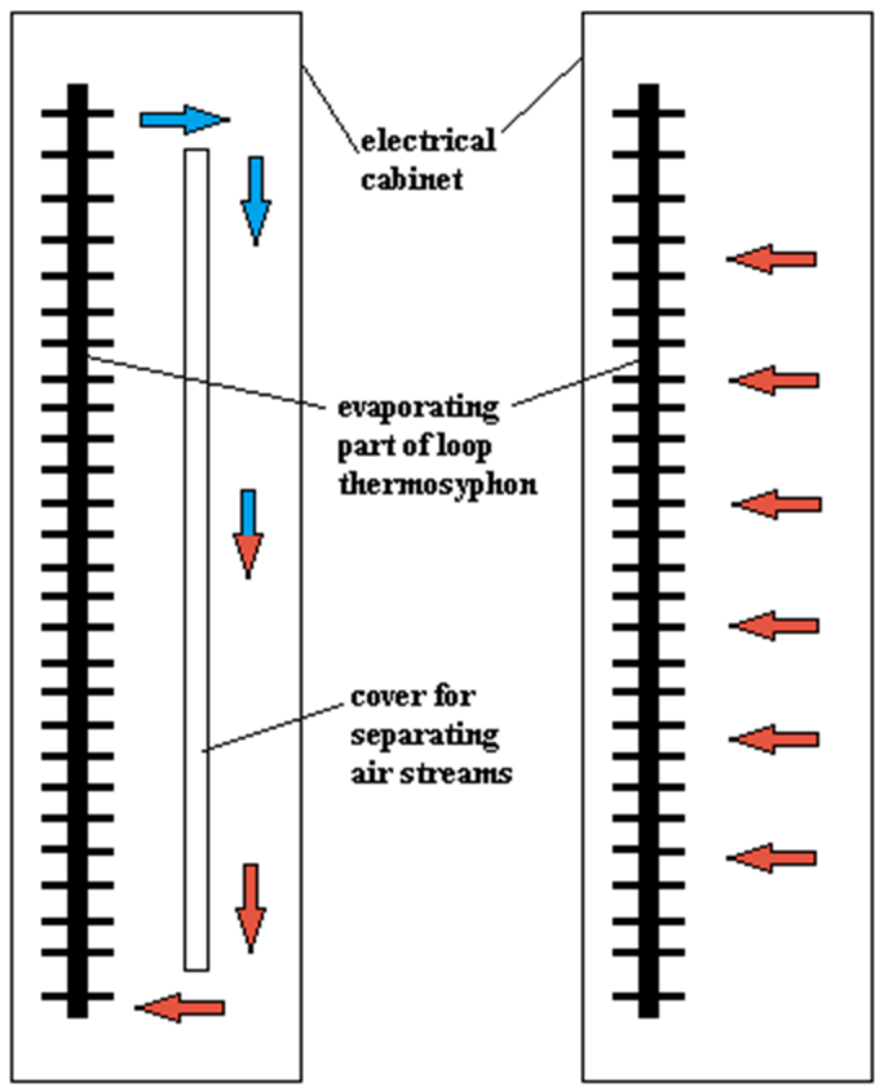

Fig. 2. Schematic representation of the evaporating part of the heat pipe with longitudinal (left) and perpendicular (right) flow direction. 
The gravity loop heat pipe is tested at different heat loads and at different types of flow. The amount of heat flow in the cabinet is produced by electric spirals, which draw energy from the power exchange. The simulated heat flux in the interior of the electrical cabinet is from 500 to $1000 \mathrm{~W}$. This heat flux is taken from the interior of the cabinet by means of a heat pipe which absorbs heat by natural or forced convection. In the case of natural air flow to the evaporating part of the heat pipe, the heat dissipation depends exclusively on the transfer properties of the heat pipe. Forced air convection is provided by fans with longitudinal and perpendicular flow to the evaporating part of the heat pipe. Longitudinal air flow is provided by 2 tangential fans, which are located in the upper and lower part of the cabinet. The individual air streams coming out of these fans are separated from each other by a cover. A fan located in the lower part of the cabinet presses air on the exchanger surface and another fan installed in the upper part of the cabinet sucks air from the space of the exchanger surface and spreads it to the centre of the cabinet, where it is heated again. The vertical air flow is ensured by 6 axial fans, which are evenly distributed over the entire surface of the evaporator. Their task is to ensure direct air flow to the evaporator and to ensure an even temperature distribution in the interior of the cabinet.

\section{Results and discussion}

The proposed system of cooling the electrical cabinet by means of a gravitational heat pipe was tested first with natural free convection of air in the interior of the cabinet and later it was supplemented by internal fans. Measurement with natural convection of air on the evaporator was started only at a power of $1000 \mathrm{~W}$ and at $80 \%$ filling of the evaporator with water. The reason was the assumption and experience from other research that the electrical cabinet will overheat at high heat loads despite the presence of a cooling system.

The temperature curves from the measurement are shown in Figure 3. It follows that the heat pipe is not able to provide heat dissipation by free convection at such a heat load. The internal temperature of the cabinet was different in each place and gradually increased until the maximum permissible temperature of $80{ }^{\circ} \mathrm{C}$ was exceeded. The amount of heat removed was $606.13 \mathrm{~W}$.

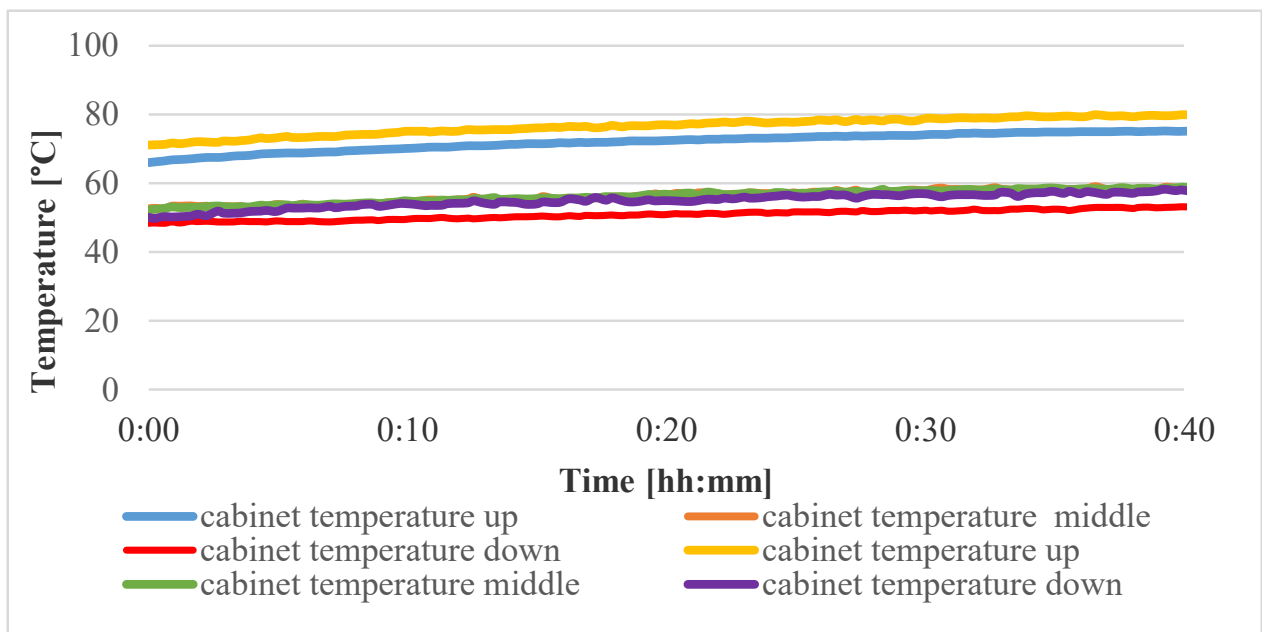

Fig. 3. The course of temperatures in the interior of the cabinet during the natural flow of air to the heat pipe. 
The result when using gravity heat pipes with free air flow to the evaporator is the fact that the evaporation part of the heat pipe cannot spontaneously receive such an amount of heat loss. For this reason, it is possible to use the system, but only at lower heat loads or to provide forced convection.

From the knowledge of air flow, it is clear that changing the type of flow from natural to forced brings the possibility of greater heat transfer and with it greater efficiency of the device. For cooling the electronic elements of the cabinet by means of a gravity heat pipe, measurements were performed with forced convection at the longitudinal and perpendicular direction of the air flow to the evaporator. Measurements were performed at all simulated heat fluxes from 500 to $1000 \mathrm{~W}$ and at different volumetric fillings of the system. The results of the measurements were recorded and subsequently evaluated in terms of the amount of heat transferred and operating temperatures in the interior of the electrical cabinet.

The longitudinal flow direction was provided by tangential fans and the resulting values of the transferred amount of heat are written in Table 1 . At the maximum load of the heat pipe, the temperature in the cabinet did not stabilize at $20 \%$ and $40 \%$ filling of the evaporator with the working substance - water. During these fillings of the system, the temperature constantly increased above the required value of $80^{\circ} \mathrm{C}$. For this reason, the performance values in the table are not recorded either, and the system was evaluated as non-functional in these cases.

Table 1. Results of measurements in the longitudinal direction of air flow to the evaporator.

\begin{tabular}{|c|c|c|c|c|c|}
\hline \multirow{2}{*}{$\begin{array}{c}\text { Simulated } \\
\text { power } \\
{[W]}\end{array}$} & \multicolumn{6}{|c|}{ Amount of heat dissipated in the direction of air flow longitudinal to } \\
the evaporator [W]
\end{tabular}

Forced convection with a perpendicular flow direction was provided by axial fans. The amounts of transferred heat that were removed by the heat pipe with the given type of fan are marked in Table 2. The maximum permissible operating temperature of $80{ }^{\circ} \mathrm{C}$ was not exceeded during all measurements. At a maximum simulated power of $1000 \mathrm{~W}$, the interior temperature reached a maximum of $52{ }^{\circ} \mathrm{C}$. It follows that the perpendicular flow direction can also be used at higher thermal loads.

Table 2. Measurement results with the direction of air flow perpendicular to the evaporator.

\begin{tabular}{|c|c|c|c|c|c|}
\hline $\begin{array}{c}\text { Simulated } \\
\text { power } \\
{[W]}\end{array}$ & \multicolumn{5}{|c|}{ The amount of heat dissipated at the direction of the air flow } \\
perpendicular to the evaporator [W]
\end{tabular}

When comparing the efficiency of individual air flow directions, the internal temperature in the cabinet was decisive. In Figure 4 it is possible to see the stabilization of the average interior temperature of the cabinet at a heat load of $1000 \mathrm{~W}$ and at the optimal filling of the evaporator with water to $60 \%$. The temperature course of the longitudinal flow is shown in Figure $4 \mathrm{left}$, where the temperature has stabilized at $76{ }^{\circ} \mathrm{C}$. The power transmitted by the heat pipe in this direction of flow was $685.2 \mathrm{~W}$. The measured values showed that the heat pipe is able to transfer the required amount of heat, but this value is 
maximum for it under the given conditions. The vertical air flow is shown in Figure 4 on the right with a stable interior temperature of a substantially lower value of $44{ }^{\circ} \mathrm{C}$. The amount of heat dissipated was $814.7 \mathrm{~W}$.

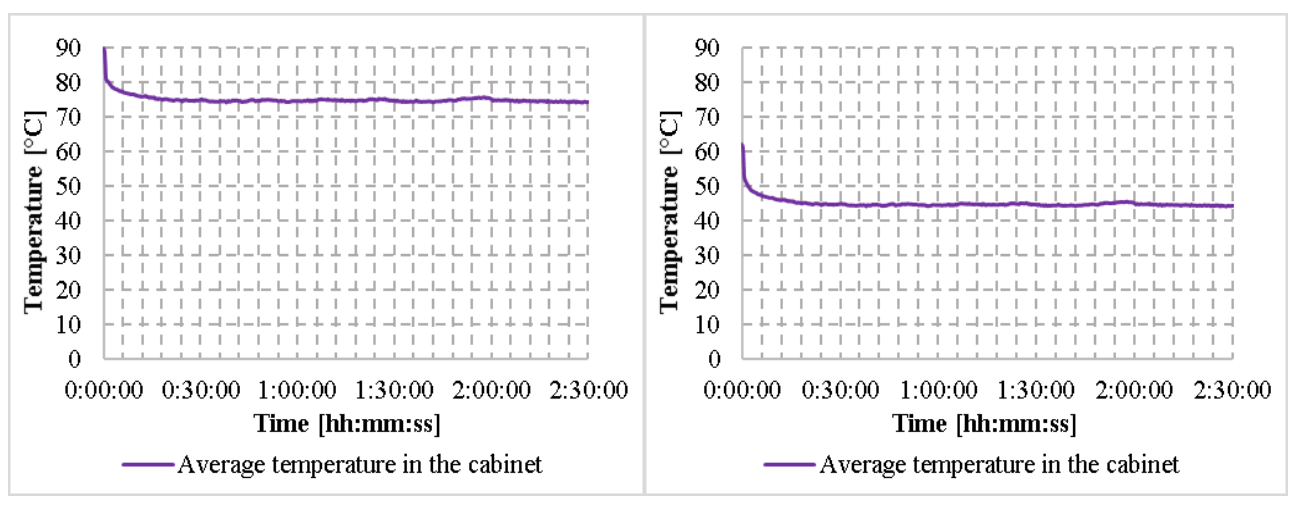

Fig. 4. Temperature profile in the interior of the cabinet at a simulated power of $1000 \mathrm{~W}$ and $60 \%$ filling of the evaporator with water at free (left) and forced (right) flow.

Based on the stabilization of the internal temperatures in the electrical cabinet, it was concluded that both methods of air flow to the evaporating part of the heat pipe dissipate the required amount of heat. The more energy-efficient flow is perpendicular, because the heat pipe has a much better efficiency and can dissipate more heat. Another positive of the vertical flow is the uniform flow of air over the entire surface of the evaporator.

\section{Conclusion}

The development of refrigeration techniques and systems is currently constantly advancing. Great emphasis is placed in the design of cooling on low-energy, maintenance-free and especially highly efficient operation of the system. The research work brings a combination of several cooling systems, which create a device capable of greater heat accumulation. The field of application of the research was focused on reducing the temperature in the spaces of electronic elements that produce waste heat during their operation.

The proposed cooling method uses a gravity loop heat pipe to cool the electronic components in the electrical cabinet. This method of passive heat dissipation is supplemented by active members - fans, which ensure the forced flow of air to the evaporating part of the heat pipe in a closed system. By including active members in the cooling system, the complete independence of the entire device from external energy sources was lost, but nevertheless the heat transfer was more intensive and more efficient. This combination of cooling system provides protection of electronic components against excessive overheating and also against dust pollution.

The research compared natural and forced cooling in cooperation with a gravitational heat pipe. The measurement results showed that the natural convection of air on the evaporator is not able to reduce the temperature inside the cabinet to the required value at a thermal load of $1000 \mathrm{~W}$. Forced air convection was provided by axial and tangential fans, where the resulting measurement values were comparably different. Very favourable results of heat dissipation were achieved by a heat pipe with a vertical air flow to the evaporator. This type of flow ensured an even distribution of temperatures in the interior of the cabinet and also sufficient cooling. 
The entire cooling system was sufficiently insulated and the individual fans provided a forced flow of air in an enclosed space. Despite the placement of active members in the passive operation of the refrigeration system, it was concluded that heat transfer was intensified, higher heat outputs were generated, the evaporator surface was not further contaminated with ambient particles and dust-free air flow to the evaporator was ensured. The proposed method of combining cooling systems is dependent on electricity, but does not represent a high financial burden.

This work has been supported by the projects KEGA 033ŽU-4/2018 "Heat sources and pollution of the environment" and 048ŽU-4/2019 "Flow visualization in environmental engineering".

\section{References}

1. V. Hlavačka, F. Polášek, Tepelné trubice v elektro-technice (1990)

2. Ó. Andrjesdóttir, Experimental characterization and optimization of a compact thermosyphon with enhanced boiling surface for power electronics cooling (2012)

3. J. Glasnák, Požadavky pro návrh chlazení elektrických rozváděču (2014)

4. P. Mindl, Aktivní chlazení elektrických rozváděču (2004)

5. Aktívne riadenie teploty v rozvádzačoch (2013)

6. Thermal Management: Enclosure Cooling Tips (2014)

7. R. Lenhard, M. Malcho, J. Jandačka, Heat transfer engineering 40 (2019)

8. P. Nemec, A. Čaja, R. Lenhard, Experimental fluid mechanics 2009, 230-235 (2009)

9. Ch. Nadjahi, H. Louahlia, S. Lemasson, Sustainable Computing: Informatics and Systems, 19, 14 (2018)

10. Ch. B. Delgado, P. D. Silva, L. C. Pires, P. D. Gaspar, Energy Procedia, 142, 3096 (2017)

11. X. Sun, L. Zhang, S. Liao, Applied Thermal Engineering, 116, 433 (2017)

12. R. Lenhard, K. Kaduchová, Š. Papučík, AIP Conference Proceedings 1608, 146 (2014)

13. P. Nemec, M. Malcho, R. Lenhard, Využitie tepelných trubic pri chladení a ohreve v technike (2015) 